\title{
Determinants of nutritional status among children under age 5 in Ethiopia: further analysis of the 2016 Ethiopia demographic and health survey
}

\author{
Zerihun Yohannes Amare*, Mossa Endris Ahmed and Adey Belete Mehari
}

\begin{abstract}
Background: The aim of this study was to examine the determinants of nutritional status among children under age 5 (0-59 months) in Ethiopia. Child malnutrition is an underlying cause of almost half (45\%) of child deaths, particularly in low socioeconomic communities of developing countries. In Ethiopia, the prevalence of stunting decreased from 47\% in 2005 to 39\% in 2016, but the prevalence of wasting changed little over the same time period (from 11 to 10\%). Despite improvements in reducing the prevalence of malnutrition, the current rate of progress is not fast enough to reach the World Health Organization global target for reducing malnutrition 40\% by 2025.

Methods: This study used data from the 2016 Ethiopia Demographic and Heath Survey (EDHS). The analysis used stunting and wasting as dependent variables, while the independent variables were characteristics of children, mothers, and households. Logistic regression was used to analyze the determinants of nutritional status among children. Bivariate analysis was also used to analyze the association between the dependent and independent variables.

Results: Study results show that child's age, sex, and perceived birth weight, mother's educational status, body mass index (BMI), and maternal stature, region, wealth quintile, type of toilet facility, and type of cooking fuel had significant associations with stunting. Child's age, sex, and perceived birth weight, mother's BMI, and residence and region showed significant associations with wasting. The study found that child, maternal, and household characteristics were significantly associated with stunting and wasting among children under age 5.

Conclusion: These findings imply that a multi-sectorial and multidimensional approach is important to address malnutrition in Ethiopia. The education sector should promote reduction of cultural and gender barriers that contribute to childhood malnutrition. The health sector should encourage positive behaviors toward childcare and infant feeding practices. More should be done to help households adopt improved types of toilet facilities and modern types of cooking fuels.
\end{abstract}

Keywords: Stunting, Wasting, Children under age 5, Demographic and health survey, Ethiopia

\footnotetext{
* Correspondence: zerihuny@bdu.edu.et; zerihun.yohannes19@gmail.com Institute of Disaster Risk Management and Food Security Studies, Bahir Dar University, Bahir Dar, Ethiopia
}

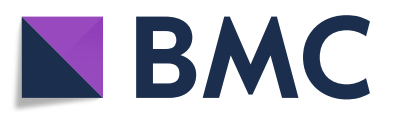

(c) The Author(s). 2019 Open Access This article is distributed under the terms of the Creative Commons Attribution 4.0 International License (http://creativecommons.org/licenses/by/4.0/), which permits unrestricted use, distribution, and reproduction in any medium, provided you give appropriate credit to the original author(s) and the source, provide a link to the Creative Commons license, and indicate if changes were made. The Creative Commons Public Domain Dedication waiver (http://creativecommons.org/publicdomain/zero/1.0/) applies to the data made available in this article, unless otherwise stated. 


\section{Introduction}

Malnutrition during childhood is the outcome of insufficient food intake, diarrhea and other infections, lack of sanitation, and low parental education $[1,2]$. Poor diets and disease are due to food insecurity, inadequate maternal and child care, and poor health services and environment [3]. These factors cause measurable adverse effects on body function and clinical outcome [4]. This problem leads to most of the anthropometric deficits found among children under age 5 in the world's least developed countries [5]. Despite existing interventions to address child malnutrition, it is still a major global public health problem [6]. Child malnutrition is an underlying cause for almost half (45\%) of child deaths, particularly in low socioeconomic communities of developing countries [7]. Globally in 2018, an estimated 149 million children under age 5 were stunted and 49 million children were wasted [8].

In sub-Saharan Africa, the prevalence of stunting is declining but remains over 30\% [8]. Among sub-Saharan countries, the prevalence of wasting in Ethiopia is $10 \%$, and the prevalence of stunting is 38\% [9]. Within Ethiopia, there is a regional variation in stunting and wasting. Amhara, Benishangul-Gumuz, Afar, and Dire Dawa are the most affected by child stunting (41-46\%), whereas wasting is highest in Somali (23\%), Afar (18\%), and Gambella (14\%) [9]. The reason may be hard-toreach areas of Afar, Somali, Benishangul-Gumuz, and Gambella were characterized by drought-related public health and nutrition problems [10]. The current rate of progress is not fast enough to reach the World Health Organization (WHO) global target of a $40 \%$ reduction in the number of stunted children by 2025 [11].

Thus to achieve this global target for 2025 in Ethiopia, a situational analysis is required to determine how many children under age 5 are stunted and wasted and to assess key determinants of malnutrition in specific social and geographical locations [11]. Among the factors that cause child malnutrition in Ethiopia are insufficient availability of food, inadequate provision of a healthy environment, such as sanitation and hygiene, women's status concerning decision-making power, and factors related to political economy $[12,13]$. Some studies have linked low birth weight, maternal short stature, household wealth quintile, place of residence, region, mother's education, child's age and sex, and perceived birth size to children's nutritional status [14, 15]. However, other studies [16-18] have found consistent disparities in the prevalence of child malnutrition in terms of children's age, sex, and birth size.

At the policy and program level, Ethiopia has many strategies and programs to reduce levels of malnutrition as part of its national development agenda. Some of the major strategies and programs include: the growth and transformation plan (GTP), National Nutrition Plan (NNP), the Seqota Declaration (SD), National Food Security Strategy, Nutrition Sensitive agriculture (NSa) strategy, school health and Nutrition Strategy (ShNS), the Productive Safety Net Program (PSNP), and Food Safety and Quality related regulatory activities [19]. The Seqota Declaration adopted Sustainable Development Goal 2 (SDG2), with the aim to end hunger, achieve food security, and improve nutrition, and promote sustainable agriculture by 2030 [20].

The Government of Ethiopia through the Ministry of Health also launched the health extension program in 2003 to achieve the country's progress in meeting the Millennium Development Goals (MDGs). The health extension workers are mainly to improve access to care in rural communities. They spend $15 \%$ of their time with infants and children under age 5 [21]. All of these listed efforts have brought positive impact in improving food and nutrition security [19]. However, there was a fragmented approach leading to inadequate multi-sectorial coordination in responding to food and nutrition demand. As a result, severe malnutrition has remained a serious challenge [19]. Thus, this finding will be used as a source of information to implement the newly introduced national food and nutrition policy. Understanding the extent and the causes of the problem will allow for appropriate planning and interventions. This study will help health practitioners and other policymakers to enable a multi-sectoral response to malnutrition by identifying its determinants among children under age 5 . This is important to achieving the Sustainable Development Goals and to meeting the global target by 2025 .

\section{Methodology \\ Data}

This study used data from the 2016 Ethiopia Demographic and Health Survey (EDHS), which was conducted by the Central Statistical Agency (CSA) of Ethiopia, with technical support from ICF. The authors have got permission from ICF-DHS program to use the EDHS data and accessed through https://www.dhsprogram.com/data/dataset_admin/login_main.cfm".

The EDHS is a population-based household survey designed to provide representative data for the country as a whole and for nine regional states and two city administrations of Ethiopia. This study considered live children age $0-59$ months with anthropometry data in the analysis of determinants of nutritional status among children under age 5 in Ethiopia. Missing values in the 2016 EDHS dataset were not included in the analyses. Notalive children (635) and children with no anthropometry data from stunting condition (1000) or wasting condition (927) were also omitted from the analysis. 


\section{Variables}

\section{Dependent variables}

The three anthropometric indicators mostly used for monitoring malnutrition in children are: stunting (low heightfor-age); underweight (low weight-for-age); and wasting (low weight-for height). However, underweight is the composite of stunting and wasting, so this study used stunting and wasting for the analysis. They were defined using the WHO child growth standards. Stunting and wasting were coded as binary variables based on the standard definitions.

\section{Independent variables}

To analyze the determinants of nutritional status among children under age 5, the study considered the following characteristics as independent variables: 1$)$ child characteristics, including age (less than 6 months, 6-11 months, 1217 months, 18-23 months, and 24-59 months), sex (male, female), birth order (first, 2-4, 5 or higher), and perceived birth weight (very small, smaller than average, average, and very large or larger than average); 2) maternal characteristics, including marital status (never married, married, widowed/divorced/separated), age at child's birth (12-19, 20-49), educational status (no education, primary, secondary and above), working status (yes, no), body mass index (underweight, normal, overweight), and maternal stature (normal stature, short stature); 3) household characteristics, including place of residence (urban, rural), region (nine regions and two city administrations), wealth quintile (poorest, poorer, middle, rich, and richest), drinking water source (improved, non-improved), toilet type (improved, nonimproved), and cooking fuel type (modern, traditional).

In the DHS, wealth quintile is calculated as an index based on consumer goods such as television, bicycle, or car. Household characteristics such as toilet facility, source of drinking water, and flooring materials are also considered in calculating the wealth index. These scores were derived using principal component analysis. Based on the 2016 EDHS, the water sources and toilet facilities were recoded as either improved or non-improved. Piped water, public taps, standpipes, tube wells, boreholes, protected dug wells and springs, and rainwater were considered as improved water sources. Non-shared toilet of the following types: flush/pour flush toilets to piped sewer systems, septic tanks, and pit latrines; ventilated improved pit (VIP) latrines; pit latrines with slabs. Composting toilets were considered as improved toilet facilities for this analysis. For household fuel type, electricity, natural gas, biogas, and kerosene were categorized as modern fuel. Charcoal, wood, animal dung, and other agricultural crops and straw were considered as traditional fuel.

\section{Statistical analysis}

Descriptive statistics were used to describe and illustrate the background characteristics of children age 0-59 months. Stata 15.1 version was used to analyze the data. Sample weights were applied in all analysis due to the twostage cluster sampling design in the EDHS dataset. Multicollinearity among independent variables was checked using variance inflation factors (VIF). Due to multicollinearity, preceding birth interval was removed from the analysis. Multiple logistic regression was used to determine the associations between predictors and nutritional outcomes after adjusting for other covariates. The study also used Pearson chi-square test for bivariate analysis.

\section{Results}

As Table 1 shows, the majority of children (61\%) were age 24-59 months, more than half (51\%) were male, and $18 \%$ were first-order births. The great majority of mothers were married (95\%), age 20-49 (90\%), and not working (72\%). About three-fourths of mothers (74\%) had normal body mass index (BMI). The large majority of households (86\%) were male-headed, and $89 \%$ were in the rural areas of Ethiopia. By region, over threequarters of children were located in just three regions: $19 \%$ in Amhara; 44\% in Oromia; and 21\% in SNNP. Nearly half of households (46\%) were in the poorest or poorer wealth quintiles, versus a third (33\%) in the richer or richest quintiles.

\section{Bivariate associations of stunting and wasting by background characteristics}

Table 2 indicates results from the bivariate analyses. Characteristics significantly associated with stunting included child's age, sex, birth order, perceived weight, maternal education, mother's BMI, place of residence, region, wealth quintile, toilet type, and fuel type. Variables associated with wasting included child's age, perceived weight, mother's BMI, region, wealth quintile, and fuel type.

\section{Factors associated with stunting}

Table 3 shows the results of the adjusted multiple logistic regressions for stunning and wasting. Child's age had a significant association with stunting. Children in the three age groups between 12 and 59 months were significantly more likely to be stunted compared with children age 0-6 months, with the highest odds found among children age 18-23 months. Female children were less likely to be stunted than male children. Children perceived as very large or larger than average in weight at birth were less likely to be stunted compared with children perceived as very small. Children of mothers with secondary and above educational attainment were less likely to be stunted compared with children of mothers with no education.

Children born of overweight and normal-BMI mothers were significantly less likely to be stunted compared with 
Table 1 Percent distribution of sampled children age 0-59 months by child's, mother's, and household characteristics, Ethiopia DHS 2016

\begin{tabular}{ll}
\hline Variables & $N(\%)$ \\
\hline Child's characteristics &
\end{tabular}

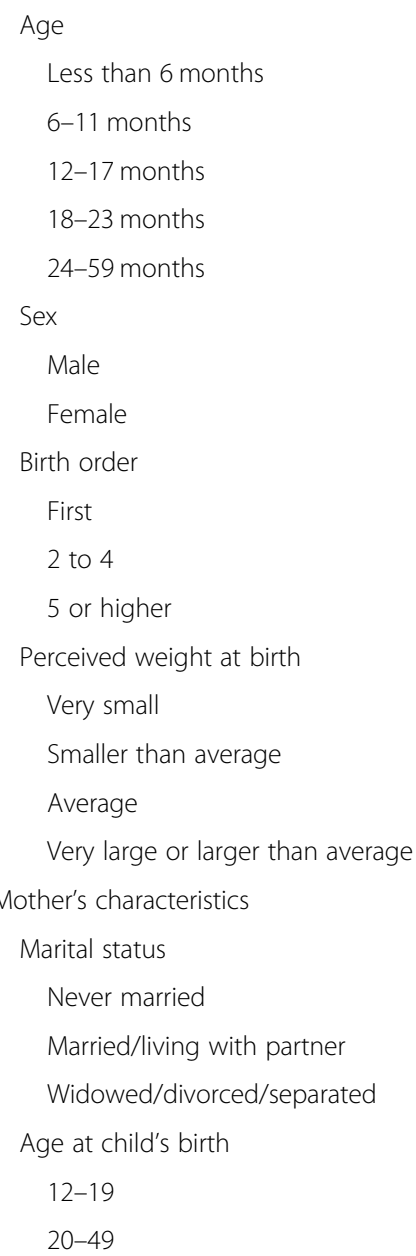

\section{Educational status}

No education

Primary

Secondary and above

Working status

No

Yes

\section{Mother's BMI}

Underweight

Normal

Overweight

Maternal stature

Normal stature

Short stature

Household characteristics

$1809(19.7)$
Table 1 Percent distribution of sampled children age 0-59 months by child's, mother's, and household characteristics, Ethiopia DHS 2016 (Continued)

\begin{tabular}{|c|c|}
\hline Variables & N (\%) \\
\hline \multicolumn{2}{|l|}{ Sex of household head } \\
\hline Male & $8137(86.4)$ \\
\hline Female & $1282(13.6)$ \\
\hline \multicolumn{2}{|l|}{ Place of residence } \\
\hline Urban & $1080(11.5)$ \\
\hline Rural & $8339(88.5)$ \\
\hline \multicolumn{2}{|l|}{ Region } \\
\hline Tigray & $620(6.6)$ \\
\hline Afar & $94(1.0)$ \\
\hline Amhara & $1774(18.8)$ \\
\hline Oromia & $4090(43.4)$ \\
\hline Somali & $426(4.5)$ \\
\hline Benishangul & $100(1.1)$ \\
\hline SNNP & $2016(21.4)$ \\
\hline Gambela & $23(0.2)$ \\
\hline Harari & $22(0.2)$ \\
\hline Addis Ababa & $215(2.3)$ \\
\hline Dire Dawa & $39(0.4)$ \\
\hline \multicolumn{2}{|l|}{ Wealth quintile } \\
\hline Poorest & $2237(23.7)$ \\
\hline Poorer & $2111(22.4)$ \\
\hline Middle & $1984(21.1)$ \\
\hline Richer & $1700(18.0)$ \\
\hline Richest & $1387(14.7)$ \\
\hline \multicolumn{2}{|l|}{ Drinking water source } \\
\hline Improved water & $5347(56.8)$ \\
\hline Non-improved water & $4072(43.2)$ \\
\hline \multicolumn{2}{|l|}{ Type of toilet } \\
\hline Improved toilet & $976(10.4)$ \\
\hline Non-improved toilet & $8443(89.6)$ \\
\hline \multicolumn{2}{|l|}{ Type of cooking fuel } \\
\hline Modern fuel & $324(3.4)$ \\
\hline Traditional fuel & 9095 (96.6) \\
\hline Total & $9419(100)$ \\
\hline
\end{tabular}

children of underweight mothers. Children of short6774 (73.8) stature mothers were more likely to be stunted compared 596 (6.5) with children of not-short-stature mothers. There was significant regional variation in stunting among children under age 5. Children from Amhara region were more likely to be stunted compared with Tigray region. In contrast, children from Addis Ababa, Gambella, and Somali regions were less likely to be stunted. Children from the richest, richer, and middle household wealth quintiles were less likely to be 
Table 2 Bivariate analysis of stunting and wasting by child's, mother's, and household characteristics

\begin{tabular}{|c|c|c|c|c|c|c|}
\hline \multirow[t]{2}{*}{ Independent Variables } & \multicolumn{6}{|c|}{ Outcome variables } \\
\hline & Stunting \% & $95 \% \mathrm{Cl}$ & $\begin{array}{l}\text { Chi2 } \\
p \text {-value }\end{array}$ & Wasting $\%$ & $95 \% \mathrm{Cl}$ & $\begin{array}{l}\text { Chi2 } \\
p \text {-value }\end{array}$ \\
\hline \multicolumn{7}{|l|}{ Children's characteristics } \\
\hline Age & & & $<0.001$ & & & $<0.001$ \\
\hline Less than 6 months & 13.6 & {$[10.0,18.3]$} & & 15.5 & {$[11.5,20.5]$} & \\
\hline 6-11 months & 17.2 & {$[13.4,21.7]$} & & 12.9 & {$[10.1,16.4]$} & \\
\hline 12-17 months & 31.7 & {$[27.7,36.1]$} & & 15.4 & {$[12.3,19]$} & \\
\hline 18-23 months & 48.6 & {$[43.2,54.1]$} & & 11.3 & {$[7.8,16.0]$} & \\
\hline 24-59 months & 45.5 & {$[42.9,48.1]$} & & 7.5 & {$[6.5,8.6]$} & \\
\hline Sex & & & $<0.001$ & & & 0.760 \\
\hline Male & 41.2 & {$[38.7,43.8]$} & & 10.1 & {$[8.8,11.6]$} & \\
\hline Female & 35.7 & {$[33.4,38.2]$} & & 9.8 & {$[8.4,11.4]$} & \\
\hline Birth order & & & 0.039 & & & 0.170 \\
\hline First & 36.1 & {$[31.8,40.7]$} & & 8.3 & {$[6.4,10.7]$} & \\
\hline 2 to 4 & 37.0 & {$[34.4,39.7]$} & & 9.7 & {$[8.2,11.5]$} & \\
\hline 5 or higher & 41.3 & {$[38.5,44.3]$} & & 11.0 & {$[9.5,12.7]$} & \\
\hline Perceived weight at birth & & & $<0.001$ & & & 0.002 \\
\hline Very small & 46.2 & {$[41.5,51]$} & & 13.4 & {$[10.9,16.5]$} & \\
\hline Smaller than average & 43.6 & {$[38.7,48.6]$} & & 12.0 & {$[9.2,15.6]$} & \\
\hline Average & 37.6 & {$[34.9,40.3]$} & & 9.6 & {$[8.2,11.2]$} & \\
\hline Very large or larger than average & 34.6 & {$[31.8,37.5]$} & & 8.2 & {$[6.8,9.9]$} & \\
\hline \multicolumn{7}{|l|}{ Mother's characteristics } \\
\hline Marital status & & & 0.771 & & & 0.531 \\
\hline Never married & 44.5 & {$[26.8,63.8]$} & & 5.2 & {$[0.8,28.1]$} & \\
\hline Married/living with partner & 38.4 & {$[36.5,40.4]$} & & 9.9 & {$[8.9,11]$} & \\
\hline Widowed/divorced/separated & 40.6 & {$[33.2,48.4]$} & & 12.0 & {$[7.8,17.9]$} & \\
\hline Age at child's birth & & & 0.111 & & & 0.478 \\
\hline $12-19$ & 42.5 & {$[37.2,48]$} & & 9.0 & {$[6.7,12]$} & \\
\hline $20-49$ & 38.1 & {$[36.1,40.5]$} & & 10.1 & {$[9.0,12.2]$} & \\
\hline Educational status & & & $<0.001$ & & & 0.051 \\
\hline No education & 41.7 & {$[39.5,44]$} & & 10.8 & {$[9.5,12.2]$} & \\
\hline Primary & 35.6 & {$[32.5,38.8]$} & & 8.7 & {$[7.1,10.7]$} & \\
\hline Secondary and above & 19.5 & {$[15.3,24.4]$} & & 7.2 & {$[4.8,10.7]$} & \\
\hline Working status & & & 0.947 & & & 0.410 \\
\hline No & 38.5 & {$[36.3,40.8]$} & & 9.7 & {$[8.5,11.0]$} & \\
\hline Yes & 38.6 & {$[35.7,41.7]$} & & 10.7 & {$[8.8,12.9]$} & \\
\hline Mother's BMI & & & $<0.001$ & & & $<0.001$ \\
\hline Underweight & 41.9 & {$[38.5,45.5]$} & & 13.5 & {$[11.3,16]$} & \\
\hline Normal & 38.9 & {$[36.5,41.3]$} & & 9.5 & {$[8.4,16]$} & \\
\hline Overweight & 24.4 & {$[19.6,29.9]$} & & 4.6 & {$[2.4,8.8]$} & \\
\hline Maternal stature & & & $<0.001$ & & & 0.396 \\
\hline Normal stature & 38.1 & {$[36.1,40.1]$} & & 9.9 & {$[8.8,11.1]$} & \\
\hline Short stature & 54.8 & {$[45.5,63.7]$} & & 12.6 & {$[7.4,20.7]$} & \\
\hline
\end{tabular}

Household characteristics 
Table 2 Bivariate analysis of stunting and wasting by child's, mother's, and household characteristics (Continued)

\begin{tabular}{|c|c|c|c|c|c|c|}
\hline \multirow[t]{2}{*}{ Independent Variables } & \multicolumn{6}{|c|}{ Outcome variables } \\
\hline & Stunting \% & $95 \% \mathrm{Cl}$ & $\begin{array}{l}\text { Chi2 } \\
p \text {-value }\end{array}$ & Wasting \% & $95 \% \mathrm{Cl}$ & $\begin{array}{l}\text { Chi2 } \\
p \text {-value }\end{array}$ \\
\hline Sex of household head & & & 0.220 & & & 0.287 \\
\hline Male & 38.4 & {$[36.4,40.6]$} & & 10.1 & {$[9.0,11.4]$} & \\
\hline Female & 39.2 & {$[35.7,42.8]$} & & 8.8 & {$[7.0,11.1]$} & \\
\hline Place of residence & & & $<0.001$ & & & 0.509 \\
\hline Urban & 26.0 & {$[21.5,31.1]$} & & 9.1 & {$[7.0,11.8]$} & \\
\hline Rural & 40.1 & {$[38.1,42.2]$} & & 10.1 & {$[9.0,11.3]$} & \\
\hline Region & & & $<0.001$ & & & $<0.001$ \\
\hline Tigray & 39.5 & {$[35.8,43.4]$} & & 11.5 & {$[9.5,13.8]$} & \\
\hline Afar & 40.9 & {$[36.5,45.5]$} & & 17.1 & {$[13.4,21.6]$} & \\
\hline Amhara & 47.6 & {$[43.8,51.4]$} & & 10.0 & {$[8.0,12.5]$} & \\
\hline Oromia & 36.1 & {$[32.8,39.5]$} & & 10.5 & {$[8.8,12.6]$} & \\
\hline Somali & 26.5 & {$[22.8,30.6]$} & & 22.2 & {$[17.5,27.8]$} & \\
\hline Benishangul & 42.9 & {$[38.2,47.6]$} & & 10.5 & {$[7.8,14.0]$} & \\
\hline SNNP & 39.6 & {$[35.7,43.6]$} & & 6.2 & {$[4.8,8.0]$} & \\
\hline Gambela & 24.1 & {$[20.3,28.4]$} & & 13.9 & {$[10.4,18.4]$} & \\
\hline Harari & 32.1 & {$[27.7,36.8]$} & & 10.7 & {$[7.4,15.2]$} & \\
\hline Addis Ababa & 14.9 & {$[11.1,19.7]$} & & 2.4 & {$[1.3,4.6]$} & \\
\hline Dire Dawa & 40.9 & {$[34.5,47.6]$} & & 10.2 & {$[7.1,14.4]$} & \\
\hline Wealth quintile & & & $<0.001$ & & & $<0.001$ \\
\hline Poorest & 45.6 & {$[42.4,48.8]$} & & 13.8 & {$[11.2,16.8]$} & \\
\hline Poorer & 42.5 & {$[38.7,46.5]$} & & 9.6 & {$[7.7,12.0]$} & \\
\hline Middle & 38.6 & {$[34,43.4]$} & & 10.4 & {$[8.2,13.1]$} & \\
\hline Richer & 34.8 & {$[31,38.7]$} & & 6.8 & {$[5.1,9.0]$} & \\
\hline Richest & 25.7 & {$[22.1,29.7]$} & & 7.7 & {$[5.7,10.2]$} & \\
\hline Drinking water source & & & 0.048 & & & 0.098 \\
\hline Improved water & 37.0 & {$[34.6,39.5]$} & & 9.2 & {$[8.0,10.5]$} & \\
\hline Non-Improved water & 40.5 & {$[37.8,43.3]$} & & 11.0 & {$[9.3,12.8]$} & \\
\hline Toilet facilities & & & $<0.001$ & & & 0.222 \\
\hline Improved toilet & 26.8 & {$[22.4,31.7]$} & & 8.5 & {$[6.5,11.1]$} & \\
\hline Non-improved toilet & 39.8 & {$[37.8,42]$} & & 10.0 & {$[9.0,11.3]$} & \\
\hline Type of cooking fuel & & & $<0.001$ & & & 0.049 \\
\hline Modern fuel & 21.4 & {$[14.9,29.9]$} & & 5.2 & {$[2.6,10.2]$} & \\
\hline Traditional fuel & 39.1 & {$[37.2,41.1]$} & & 10.1 & {$[9.1,11.3]$} & \\
\hline
\end{tabular}

stunted compared with children from the poorer and poorest quintiles. Children in households with non-improved toilet facilities were more likely to be stunted compared with those with improved toilet facilities. Children in households with traditional cooking fuel type were more likely to be stunted compared with those with modern fuel type.

\section{Factors associated with wasting}

Table 3 also presents results of the adjusted multiple logistic regression for wasting. Children age 24-59 months were significantly less likely to be wasted compared with children age 0-6 months. Children with larger than average weight at birth and children with average perceived weight at birth were less likely to be wasted compared with children with perceived as very small at birth. Female children were less likely to be wasted than male children. Children whose mothers were overweight or of normal BMI had lower odds of being wasted compared with children of underweight mothers. Rural children were less likely to be wasted compared with urban 
Table 3 Prevalence of stunting and wasting among children age 0-59 months by children's, mother's, and household characteristics

\begin{tabular}{|c|c|c|c|}
\hline \multirow[t]{3}{*}{ Independent variables } & & \multicolumn{2}{|l|}{ Outcome variables } \\
\hline & & \multirow{2}{*}{$\begin{array}{l}\text { Stunting } \\
\text { AOR }(95 \% \mathrm{Cl})\end{array}$} & \multirow{2}{*}{$\begin{array}{l}\text { Wasting } \\
\text { AOR }(95 \% \mathrm{Cl})\end{array}$} \\
\hline & & & \\
\hline \multicolumn{4}{|l|}{ Children's characteristics } \\
\hline \multirow[t]{5}{*}{ Age } & Less than 6 months & 1 & 1 \\
\hline & 6-11 months & $1.34(0.97-1.86)$ & $1.10(0.82-1.50)$ \\
\hline & 12-17 months & $3.50^{* * *}(2.59-4.74)$ & $1.13(0.84-1.52)$ \\
\hline & 18-23 months & $7.81^{* * *}(5.73-10.65)$ & $0.87(0.62-1.21)$ \\
\hline & 24-59 months & $6.59 * * *(5.00-8.68)$ & $0.56^{* * *}(0.43-0.73)$ \\
\hline \multirow[t]{2}{*}{ Sex } & Male & 1 & 1 \\
\hline & Female & $0.82^{* * *}(0.74-0.90)$ & $0.77^{* * *}(0.67-0.88)$ \\
\hline \multirow[t]{3}{*}{ Birth order } & First & 1 & 1 \\
\hline & 2 to 4 & $1.02(0.87-1.20)$ & $1.02(0.80-1.29)$ \\
\hline & 5 or higher & $1.16(0.97-1.39)$ & $1.16(0.90-1.50)$ \\
\hline \multirow[t]{4}{*}{ Perceived weight at birth } & Very small & 1 & 1 \\
\hline & Smaller than average & $0.82^{*}(0.67-0.99)$ & $1.07(0.83-1.37)$ \\
\hline & Average & $0.68^{* * *}(0.59-0.78)$ & $0.71^{* * *}(0.59-0.86)$ \\
\hline & Very large or larger than average & $0.54 * *(0.47-0.63)$ & $0.60^{* * *}(0.49-0.74)$ \\
\hline \multicolumn{4}{|l|}{ Mother's characteristics } \\
\hline \multirow[t]{3}{*}{ Marital status } & Never in union & 1 & 1 \\
\hline & Married/living with partner & $0.72(0.38-1.39)$ & $2.16(0.51-9.14)$ \\
\hline & Widowed/divorced/ separated & $0.64(0.32-1.26)$ & $2.48(0.57-10.76)$ \\
\hline \multirow[t]{2}{*}{ Age } & $12-19$ & 1 & 1 \\
\hline & $20-49$ & $0.97(0.81-1.16)$ & $0.96(0.74-1.25)$ \\
\hline \multirow[t]{3}{*}{ Educational status } & No education & & \\
\hline & Primary & $0.97(0.86-1.10)$ & $0.92(0.76-1.11)$ \\
\hline & Secondary and above & $0.66^{* * *}(0.52-0.84)$ & $0.80(0.57-1.13)$ \\
\hline \multirow[t]{2}{*}{ Working status } & No & 1 & 1 \\
\hline & Yes & $1.02(0.91-1.14)$ & $1.08(0.91-1.28)$ \\
\hline \multirow[t]{3}{*}{ Mother's BMI } & Underweight & & \\
\hline & Normal & $0.84^{* *}(0.74-0.94)$ & $0.67^{* * *}(0.57-0.78)$ \\
\hline & Overweight & $0.57^{* * *}(0.45-0.71)$ & $0.39^{* * *}(0.28-0.55)$ \\
\hline \multirow[t]{2}{*}{ Maternal stature } & Normal stature & 1 & 1 \\
\hline & Short stature & $2.03^{* * *}(1.44-2.86)$ & $1.08(0.65-1.80)$ \\
\hline \multicolumn{4}{|l|}{ Households characteristics } \\
\hline \multirow[t]{2}{*}{ Sex of household head } & Male & 1 & 1 \\
\hline & Female & $1.07(0.94-1.23)$ & $0.97(0.81-1.17)$ \\
\hline \multirow[t]{2}{*}{ Place of Residence } & Urban & 1 & 1 \\
\hline & Rural & $0.86(0.69-1.07)$ & $0.61(0.64-1.10)$ \\
\hline \multirow[t]{6}{*}{ Region } & Tigray & 1 & 1 \\
\hline & Afar & $0.87(0.69-1.10)$ & $1.33(0.97-1.81)$ \\
\hline & Amhara & $1.27^{*}(1.03-1.58)$ & $0.87(0.62-1.20)$ \\
\hline & Oromia & $0.83(0.68-1.01)$ & $1.00(0.75-1.34)$ \\
\hline & Somali & $0.52^{* * *}(0.42-0.65)$ & $2.02^{* * *}(1.51-2.68)$ \\
\hline & Benishangul & $1.13(0.90-1.43)$ & $0.97(0.69-1.37)$ \\
\hline
\end{tabular}


Table 3 Prevalence of stunting and wasting among children age 0-59 months by children's, mother's, and household characteristics (Continued)

\begin{tabular}{|c|c|c|c|}
\hline \multirow[t]{3}{*}{ Independent variables } & & \multicolumn{2}{|l|}{ Outcome variables } \\
\hline & & \multirow{2}{*}{$\begin{array}{l}\text { Stunting } \\
\text { AOR }(95 \% \mathrm{Cl})\end{array}$} & \multirow{2}{*}{$\begin{array}{l}\text { Wasting } \\
\text { AOR }(95 \% \mathrm{Cl})\end{array}$} \\
\hline & & & \\
\hline & SNNP & $0.99(0.80-1.21)$ & $0.60^{* *}(0.43-0.85)$ \\
\hline & Gambela & $0.51^{* * *}(0.39-0.66)$ & $1.19(0.84-1.67)$ \\
\hline & Harari & $0.87(0.67-1.15)$ & $1.20(0.81-1.76)$ \\
\hline & Addis Ababa & $0.64^{*}(0.43-0.94)$ & $0.35^{* *}(0.17-0.76)$ \\
\hline & Dire Dawa & $1.09(0.83-1.43)$ & $0.83(0.55-1.27)$ \\
\hline \multirow[t]{5}{*}{ Wealth quintile } & Poorest & 1 & 1 \\
\hline & Poorer & $1.01(0.86-1.17)$ & $0.88(0.71-1.10)$ \\
\hline & Middle & $0.77^{* *}(0.65-0.91)$ & $0.92(0.72-1.16)$ \\
\hline & Richer & $0.69 * * *(0.58-0.82)$ & $0.66^{* *}(0.50-0.87)$ \\
\hline & Richest & $0.62^{* * *}(0.49-0.79)$ & $0.58^{* *}(0.40-0.83)$ \\
\hline \multirow[t]{2}{*}{ Drinking water source } & Improved water & 1 & 1 \\
\hline & Non-improved water & $0.91(0.81-1.01)$ & $1.00(0.86-1.17)$ \\
\hline \multirow[t]{2}{*}{ Type of toilet facilities } & Improved toilet & 1 & 1 \\
\hline & Non-improved toilet & $1.28^{* *}(1.07-1.53)$ & $1.06(0.83-1.36)$ \\
\hline \multirow[t]{2}{*}{ Type of cooking fuel } & Modern fuel & 1 & 1 \\
\hline & Traditional fuel & $1.66^{* *}(1.18-2.32)$ & $1.28(0.74-2.21)$ \\
\hline
\end{tabular}

${ }^{* * *} p<0.001,{ }^{* *} p<0.01,{ }^{*} p<0.05$, AOR: adjusted odds ratio

children. Children in households in Addis Ababa and SNNP had lower odds of being wasted compared with children in Tigray region, while children in households in Somali region had higher odds of being wasted.

\section{Discussion}

This study assessed the determinants of nutritional status among children under age 5 in Ethiopia. Study results show that child's age, sex, and perceived birth weight, mother's educational status, BMI, and maternal stature, and region, wealth quintile, type of toilet facility, and type of cooking fuel had significant associations with stunting. Child's age, sex, and perceived birth weight, mother's BMI, and residence and region showed significant associations with wasting.

This study shows that the risk of stunting increased with age of child. Previous studies in Ethiopia have shown similar results [22-24]. The reason might be that as children grow older they have greater energy needs. Besides, stunting reflects chronic malnutrition that can be manifested after long-term nutritional deficiency, while wasting reflects acute undernutrition. As child's age increase, there is the probability that the child will receive childhood vaccinations, which reduce exposure to disease. For example [25] found that children vaccinated against measles are less likely to be wasted.

In Ethiopia as in many developing countries, complementary feeding is a challenge for children age 6-23 months
[26]. Studies in other developing countries [26-28] found that complementary foods given to infants in the second 6 months of age and beyond are often inadequate in energy density.

In our study, female children were less likely to be stunted and wasted than boys. This finding is consistent with a meta-analysis in sub-Saharan Africa [16], a study in the Northern Ethiopia [29], and research in Myanmar [30]. However, it is contrary to findings of studies in Tanzania [31], Pakistan [32], India [33], and Kenya [34] that girls had a higher prevalence of stunting than boys. Example $[16,35,36]$ found that sex differences in nutritional status might be due to biological differences in morbidity between boys and girls in their early life. This may also apply to our findings on wasting. A review of complementary feeding reported that boys have higher birth weights than girls and grow faster during infancy, resulting in greater energy needs [36]. Furthermore, another study on Guatemalan infants reported that women perceived male children to be hungrier and less likely to be satisfied by breastfeeding alone [37], placing them at increased risk of infections.

Regarding our findings on perceived weight of child at birth, the risks of stunting and wasting were higher among children perceived to have low birth weight. These findings are consistent with previous studies in Zambia [38], Bangladesh [39-41], India [42], Malaysia [43], and Indonesia [44], and may be due to the poor 
nutrition of mothers during pregnancy. This finding is supported by our results of the association between mother's BMI and stunting and wasting in children. Ramakrishnan [45] reported that children born of overweight mothers are less likely to be stunted and wasted due to adequacy of protein and energy intakes of mothers during pregnancy [45]. A similar study in Nepal [46] also showed that as maternal BMI increased there was a reduction in children's stunting, and wasting.

Our study found that children born to mothers with short stature were more likely to be stunted. This result is in line with previous studies in South Africa [14]; and Ghana [15]. This association reflects the fact that women who were stunted during their own childhood are more likely to give birth to stunted children [47].

Higher level of mothers' educational attainment was positively associated with stunting in children. This is in line with previous related studies in the Philippines [48], Libya [49], Ethiopia [24], Uganda [50], Mozambique [51], and Ghana [15]. As stated in different studies, the reasons include that educated women are better informed about optimal child care practices [52], have better hygiene practices [53, 54], feeding [55], and childcare during illness [55-57], have a greater ability to use the health system [58], and are more empowered to make decisions [53]. In our study, however, in about two-thirds of cases (65\%), the mothers had not attended formal education, and as a result their knowledge on childcare may not have been enough.

Our study found regional variation in stunting and wasting in Ethiopia. Compared with Tigray, the reference region, children from Addis Ababa were less likely to be either stunted or wasted, while children in Gambella were less likely to be stunted, and children in SNNP were less likely to be wasted. Interestingly, children in the Somali region were less likely to be stunted but more likely to be wasted compared with Tigray. This could be because wasting is characterized by acute malnutrition that can be caused by temporary increased food insecurity from extreme weather events, drought, and shifts in agricultural practices [59, 60]. Previous research in Ethiopia [61] showed the association between malnutrition varied across regions due to variation in cultivated area.

We found that children from the richest, richer, and middle household wealth quintiles were less likely to be stunted compared with children from the poorer and poorest quintiles. As mentioned, in the DHS surveys household wealth is measured as an index reflecting household material living standards, which include the types of water sources and sanitation facilities used by the household. Our study found that children in households with non-improved toilet facilities and traditional fuel types were more likely to be stunted. Previous studies in Nepal [62] and other Asian countries [63] have found that household asset accumulation is an important predictor of nutritional improvement.
Environmental factors such as unimproved water, unimproved sanitation, and biomass fuel are the second largest global attributable burden as cause of child stunting [64]. A study of 137 developing countries reported that an estimated 7.2 million cases of stunting were attributable to unimproved sanitation [64]. In Ethiopia, more than half of rural households (56\%) use unimproved toilet facilities [9]. In rural areas of Ethiopia, more than one in three households (39\%) have no toilet facility, versus 7\% in urban areas [9]. Related studies in Sri Lanka [65-68] revealed that malnutrition among children is still a major health problem associated with poor sanitation and personal hygiene. However, a study conducted in rural Zimbabwe [69] found improved water, sanitation, and hygiene interventions in rural areas in low-income countries were unlikely to reduce stunting more than the effect of improved infant and child feeding alone. This implies integration of improved infant diets with improved water, sanitation, and hygiene is a logical approach to improve nutritional status of under-five children.

The great majority of Ethiopian households (93\%) use traditional fuels such as wood, charcoal, and dung cake to meet their daily needs, and most households (59\%) cook food outside [10]. Indoor air pollution and smoking are causes of low birth weight and could possibly impact stunting [45]. Another study in India reported associations between air pollution and stunting [70]; children living in households using biofuel were more likely to be stunted compared with children living in households using cleaner fuels ([70]).

\section{Strengths and limitations}

The strength of this study was that it used nationally representative sample from urban and rural settings of the nine regional states and two urban administrations which allow generalization of the results. Therefore, these study findings could help as an intervention to policy makers, charity organizations across the globe for places having similar settings. It also applied all of the DHS data principles, like weighting. Regarding limitations, the crosssectional data cannot examine causation or seasonal variation of nutritional outcomes. The other limitation is that during DHS data collection measurements of children's height obtained by laying down children under age 2 may considered as a source of human error.

\section{Conclusion and policy implications}

Our study found that child, maternal, and household characteristics were significantly associated with stunting and wasting among of children under age 5. Despite efforts made by the Ethiopian government and improvements in reducing malnutrition, rates of stunting and wasting remain high. The consequences of child malnutrition are 
grave and include poor performance in school and low adult economic productivity. The findings imply that a multi-sectorial and multidimensional approach is important to address malnutrition in Ethiopia. The education sector should promote maternal education and policies to reduce cultural and gender barriers. The health sector should provide health education to families to encourage positive behaviors toward childcare and infant feeding practices. In addition, the health and human services sectors can promote use of improved toilets. To reduce stunting due to traditional fuel usage in households, the energy sector should help households to access clean energy. Further research is suggested to explore the impact of seasonal food insecurity and climatic events on stunting and wasting and to examine the associated factors affecting nutritional status among children over time, using decomposition analysis.

\begin{abstract}
Acknowledgments
Foremost, we would like to thank USAID for the DHS data analysis training through the 2019 DHS Fellows program implemented by ICF. We give thanks to our facilitators Dr. Shireen Assaf and Dr. Wenjuan Wang. Their scholarly guidance and encouragement was the source of energy for our research. We would like to express our special thanks to our co-facilitators, Mr. Gedefaw Abeje Fekade, and Dr. Kyaw Swa Mya for their invaluable assistance to improve our research during the training. We especially appreciate the support of Dr. Sorrel Namaste for her advice and sharing valuable materials at the inception that supports our inclusion criteria during sampling procedure. We also appreciate Dr. Rukundo Benedict and Yodit Bekele for their valuable comments and their time spent in sharing related materials to improve our work. The last but not the least, we appreciate the support of Bryant Robey and Joan Wardell for editing the language.
\end{abstract}

\section{Ethics approval and consent to particpate}

The authors have got permission from ICF-DHS program to use the EDHS data and accessed through: https://www.dhsprogram.com/data/dataset_ admin/login_main.cfm. The ICF-DHS collected the data after having permission from the concerned Ethiopian government authorized bodies.

\section{Authors' contributions}

ZYM contributed in conceptualization and development of the proposal, data curation and formal analysis. MEH and ABM contributed in reviewing the proposal, participate in data analysis and interpretation. All authors read and approved the final manuscript.

\section{Funding}

The authors received no specific funding for this work.

\section{Availability of data and materials}

The weighted data used for the analysis can be obtained from the corresponding author up on reasonable request.

\section{Consent for publication}

Not applicable.

\section{Competing interests}

The authors declare that they have no competing interests.

Received: 28 August 2019 Accepted: 11 October 2019

Published online: 06 November 2019

\section{References}

1. Tibilla MA. The nutritional impact of the world food programmesupported supplementary feeding programme on children less than five years in rural tamale, Ghana 17-18; 2007.
2. Birara MY, Amsalu BA. Prevalence and factors associated with stunting, underweight and wasting: a community based cross sectional study among children age 6-59 Months at Lalibela Town, Northern Ethiopia; 2014.

3. UNAC. United Nations. Administrative committee on co-ordination. Subcommittee on NutritionThird report on the world nutrition situation. United Nations: ACC/SCN Secretariat; 1997.

4. WHO. World Health Organization child growth standards and the identification of severe acute malnutrition in infants and children: joint statement by the World Health Organization and the United Nations Children's Fund. 2009

5. WHO. World Health Organization, and UNICEF. Global prevalence of vitamin A deficiency. No. WHO/NUT/95, vol. 3. Geneva: World Health Organization; 1995.

6. Akombi BJ, Agho KE, Merom D, Renzaho AM, Hall JJ. Child malnutrition in sub-Saharan Africa: a meta-analysis of demographic and health surveys (2006-2016). PLoS One. 2017;12(5):e0177338.

7. Black RE, Victora CG, Walker SP, Bhutta ZA, Christian P, et al. Maternal and child undernutrition and overweight in low-income and middle-income countries. Lancet. 2013;382(9890):427-51.

8. UNICEF. Levels and trends in child malnutrition, United Nations Children's fund (UNICEF), World Health Organization, International Bank for Reconstruction and Development/The World Bank. Levels and trends in child malnutrition: key findings of the 2019 edition of the joint child malnutrition estimates. Geneva: World Health Organization; 2019 Licence: CC BY-NC-SA 3.0 IGO; 2019.

9. CSA I. Central statistical agency (CSA) [Ethiopia] and ICF, Ethiopia demographic and health survey, Addis Ababa, Ethiopia and Calverton, Maryland, USA: . 2016.

10. UNICEF. UNICEF annual report Ethiopia. 2017

11. WHO. World Health Organization,Global nutrition targets 2025: Stunting policy brief. World Health Organization; 2014.

12. Shroff M, Griffiths P, Adair L, Suchindran C, Bentley M. Maternal autonomy is inversely related to child stunting in Andhra Pradesh, India. Matern Child Nutr. 2009;5(1):64-74.

13. Hutton $\mathrm{G}$, Chase $\mathrm{C}$. The knowledge base for achieving the sustainable development goal targets on water supply, sanitation and hygiene. Int J Environ Res Public Health. 2016;13(6):536.

14. Mamabolo RL, Alberts M, Steyn NP, Delemarre-van de Waal HA, Levitt NS. Prevalence and determinants of stunting and overweight in 3-year-old black south African children residing in the central region of Limpopo Province, South Africa. Public Health Nutr. 2005;8(5):501-8.

15. Novignon J, Aboagye E, Agyemang OS, Aryeetey G. Socioeconomic-related inequalities in child malnutrition: evidence from the Ghana multiple indicator cluster survey. Heal Econ Rev. 2015;5(1):34.

16. Wamani H, Åstrøm AN, Peterson S, Tumwine JK, Tylleskär T. Boys are more stunted than girls in sub-Saharan Africa: a meta-analysis of 16 demographic and health surveys. BMC Pediatr. 2007;7(1):17.

17. Uthman OA. Decomposing socio-economic inequality in childhood malnutrition in Nigeria. Matern Child Nutr. 2009;5(4):358-67.

18. Gayle HD, Dibley MJ, Marks JS, Trowbridge FL. Malnutrition in the first two years of life: the contribution of low birth weight to population estimates in the United States. Am J Dis Child. 1987;141(5):531-4.

19. FDRE Food and Nutrtion Policy. Federal Democratic Republic of Ethiopia, Food and Nutrtion Policy, Addis Ababa, Ethiopia. 2018.

20. SeqotaDeclaration. Federal Democratic Republic of Ethiopia (FDRE). Seqota declaration implementation plan (2016-2030): Summary program approach document. Addis Ababa: FDRE; 2016.

21. Mangham-Jefferies L, Mathewos B, Russell J, Bekele A. How do health extension workers in Ethiopia allocate their time? Hum Resour Health. 2014;12(1):61

22. Genebo T, Girma W, Haider J, Demisse T. Factors contributing to positive and negative deviances in child nutrition. Ethiop J Health Dev. 1998;12(2):69-74.

23. Asfaw ST, Giotom L. Malnutrition and enteric parasitoses among under-five children in Aynalem Village, Tigray. Ethiop J Health Dev. 2000;14(1):67-75.

24. Yimer G. Malnutrition among children in Southern Ethiopia: Levels and risk factors. Ethiop J Health Dev. 2000;14(3):283-92.

25. Mekonnen A, Jones N, Tefera B, editors. Tackling child malnutrition in Ethiopia: do the sustainable development poverty reduction programme's underlying policy assumptions reflect local realities?: Working papers N O 19; 2005.

26. Abeshu MA, Lelisa A, Geleta B. Complementary feeding: review of recommendations, feeding practices, and adequacy of homemade complementary food preparations in developing countries-lessons from Ethiopia. Front Nutr. 2016:3:41. 
27. Caulfield LE, Huffman SL, Piwoz EG. Interventions to improve intake of complementary foods by infants 6 to 12 months of age in developing countries: impact on growth and on the prevalence of malnutrition and potential contribution to child survival. Food Nutr Bull. 1999:20(2):183-200.

28. Mora JO, Nestel PS. Improving prenatal nutrition in developing countries: strategies, prospects, and challenges. Am J Clin Nutr. 2000;71(5):1353S-63S

29. Alemayehu M, Tinsae F, Haileslassie K, Seid O, Gebregziabher G, Yebyo H. Undernutrition status and associated factors in under-5 children, in Tigray, northern Ethiopia. Nutrition. 2015;31(7-8):964-70.

30. Mya KS, Kyaw AT, Tun T. Feeding practices and nutritional status of children age 6-23 months in Myanmar: a secondary analysis of the 2015-16 demographic and health survey. PLoS One. 2019;14(1):e0209044.

31. Mbago MC, Namfua PP. Some determinants of nutritional status of one-to four-year-old children in low income urban areas in Tanzania. J Trop Pediatr. 1992;38(6):299-306.

32. Baig-Ansari N, Rahbar MH, Bhutta ZA, Badruddin SH. Child's gender and household food insecurity are associated with stunting among young Pakistani children residing in urban squatter settlements. Food Nutr Bull. 2006;27(2):114-27.

33. Mittal A, Singh J, Ahluwalia S. Effect of maternal factors on nutritional status of 1-5-year-old children in urban slum population. Indian J Community Med. 2007;32(4):264

34. Gewa CA, Yandell N. Undernutrition among Kenyan children: contribution of child, maternal and household factors. Public Health Nutr. 2012;15(6):1029-38.

35. Garenne. Sex differences in health indicators among children in African DHS surveys. J Biosoc Sci. 2003;35(4):601-14.

36. Bork KA, Diallo A. Boys are more stunted than girls from early infancy to 3 years of age in rural Senegal. J Nutr. 2017;147(5):940-7.

37. Tumilowicz A, Habicht J-P, Pelto G, Pelletier DL. Gender perceptions predict sex differences in growth patterns of indigenous Guatemalan infants and young children. Am J Clin Nutr. 2015;102(5):1249-58.

38. Masiye F, Chama C, Chitah B, Jonsson D. Determinants of child nutritional status in Zambia: an analysis of a national survey. Zambia Soc Sci J. 2010;1(1):4.

39. Islam MM, Alam M, Tariquzaman M, Kabir MA, Pervin R, Begum M, et al. Predictors of the number of under-five malnourished children in Bangladesh: application of the generalized poisson regression model. BMC Public Health. 2013;13(1):11.

40. Jesmin A, Yamamoto SS, Malik AA, Haque MA. Prevalence and determinants of chronic malnutrition among preschool children: a cross-sectional study in Dhaka City, Bangladesh. J Health Popul Nutr. 2011;29(5):494.

41. Dhar B, Mowlah G, Nahar S, Islam N. Birth-weight status of newborns and its relationship with other anthropometric parameters in a public maternity hospital in Dhaka, Bangladesh. J Health Popul Nutr. 2002;20(1)36-41.

42. Mishra K, Kumar P, Basu S, Rai K, Aneja S. Risk factors for severe acute malnutrition in children below 5 y of age in India: a case-control study. Indian J Pediatr. 2014;81(8):762-5.

43. Wong HJ, Moy FM, Nair S. Risk factors of malnutrition among preschool children in Terengganu, Malaysia: a case control study. BMC Public Health. 2014;14(1):785

44. Rahman MS, Howlader T, Masud MS, Rahman ML. Association of low-birth weight with malnutrition in children under five years in Bangladesh: do mother's education, socio-economic status, and birth interval matter? PLoS One. 2016:11(6):e0157814.

45. Ramakrishnan. Nutrition and low birth weight: from research to practice. Am J Clin Nutr. 2004;79(1):17-21.

46. Pramod Singh G, Nair M, Grubesic RB, Connell FA. Factors associated with underweight and stunting among children in rural Terai of eastern Nepal. Asia Pac J Public Health. 2009;21(2):144-52.

47. Martorell $\mathrm{R}$, Zongrone A. Intergenerational influences on child growth and undernutrition. Paediatr Perinat Epidemiol. 2012;26(1):302-314.

48. Aguillon DB, Caedo MM, Arnold JC, Engel R. The relationship of family characteristics to the nutritional status of pre-school children. Food Nutr Bull. 1982;4(4):1-8.

49. Popkin BM, Bisgrove EZ. Nutrition and urbanization (part 2): urbanization and nutrition in low-income countries. Food Nutr Bull. 1988;10(1):-1, 22.

50. Wamani H, Tylleskär T, Åstrøm AN, Tumwine JK, Peterson S. Mothers' education but not fathers' education, household assets or land ownership is the best predictor of child health inequalities in rural Uganda. Int J Equity Health. 2004;3(1):9.

51. Burchi. Child nutrition in Mozambique in 2003: the role of mother's schooling and nutrition knowledge. Econ Hum Biol. 2010;8(3):331-45.
52. Oyekale AS. Factors explaining acute malnutrition among under-five children in sub-Sahara Africa (SSA). Life Sci J. 2012;9:2101-7.

53. Keats. Women's schooling, fertility, and child health outcomes: evidence from Uganda's free primary education program. J Dev Econ. 2018;135:142-59.

54. Smith LC, Haddad LJ. Explaining child malnutrition in developing countries: a cross-country analysis: Intl Food Policy Res Inst; 2000.

55. Mukabutera A, Thomson DR, Hedt-Gauthier BL, Basinga P, Nyirazinyoye L, Murray M. Risk factors associated with underweight status in children under five: an analysis of the 2010 Rwanda demographic health survey (RDHS). BMC Nutr. 2016;2(1):40.

56. Bhutta ZA, Ahmed T, Black RE, Cousens S, Dewey K, Giugliani E, et al. What works? Interventions for maternal and child undernutrition and survival. Lancet. 2008;371(9610):417-40.

57. Iannotti LL, Dulience SJL, Green J, Joseph S, François J, Antenor M-L, et al. Linear growth increased in young children in an urban slum of Haiti: a randomized controlled trial of a lipid-based nutrient supplement. Am J Clin Nutr. 2013;99(1):198-208

58. Sunguya BF, Poudel KC, Mlunde LB, Urassa DP, Yasuoka J, Jimba M. Poor nutrition status and associated feeding practices among HIV-positive children in a food secure region in Tanzania: a call for tailored nutrition training. PLoS One. 2014;9(5):e98308.

59. Swinburn BA, Kraak VI, Allender S, Atkins VJ, Baker PI, Bogard JR, et al. The global Syndemic of obesity, undernutrition, and climate change: the lancet commission report. Lancet. London: England. 2019.

60. McCarthy JJ, Canziani OF, Leary NA, Dokken DJ, White KS, editors. Climate change 2001: impacts, adaptation, and vulnerability: contribution of Working Group II to the third assessment report of the Intergovernmental Panel on Climate Change. London: Cambridge University Press; 2001.

61. Pelletier DL, Deneke K, Kidane Y, Haile B, Negussie F. The food-first bias and nutrition policy: lessons from Ethiopia. Food Policy. 1995;20(4):279-98.

62. Headey DD, Hoddinott J. Understanding the rapid reduction of undernutrition in Nepal, 2001-2011. PLoS One. 2015;10(12):e0145738.

63. Headey D, Hoddinott J, Park S. Drivers of nutritional change in four south Asian countries: a dynamic observational analysis. Matern Child Nutr. 2016;12:210-8.

64. Danaei G, Andrews KG, Sudfeld CR, Fink G, McCoy DC, Peet E, et al. Risk factors for childhood stunting in 137 developing countries: a comparative risk assessment analysis at global, regional, and country levels. PLoS Med. 2016;13(11):e1002164.

65. De Silva N, De Silva H, Jayapani V. Intestinal parasitoses in the Kandy area, Sri Lanka. Southeast Asian J Trop Med Public Health. 1994;25:469.

66. Sorensen E, Ismail M, Amarasinghe D, Hettiarachchi I, Dassenaieke T. The prevalence and control of soil-transmitted nematode infections among children and women in the plantations in Sri Lanka. Ceylon Med J. 1996;41(2):37-41.

67. Gunawardena G, Karunaweera N, Ismail M. Socio-economic and behavioural factors affecting the prevalence of Ascaris infection in a low-country tea plantation in Sri Lanka. Ann Trop Med Parasitol. 2004;98(6):615-21.

68. Gunawardena K, Kumarendran B, Ebenezer R, Gunasingha MS, Pathmeswaran A, De Silva N. Soil-transmitted helminth infections among plantation sector schoolchildren in Sri Lanka: prevalence after ten years of preventive chemotherapy. PLoS Negl Trop Dis. 2011;5(9):e1341.

69. Humphrey, Mduduzi N N Mbuya, Robert Ntozini, Lawrence H Moulton, Rebecca J Stoltzfus, Naume V Tavengwa, et al. Independent and combined effects of improved water, sanitation, and hygiene, and improved complementary feeding, on child stunting and anaemia in rural Zimbabwe: a cluster-randomised tria for the Sanitation Hygiene Infant Nutrition Efficacy 2018.

70. Mishra V, Retherford R. Children living in households using only biofuels than among children living in households using only cleaner fuels. Int J Epidemiol. 2007;117-129(2007):36.

\section{Publisher's Note}

Springer Nature remains neutral with regard to jurisdictional claims in published maps and institutional affiliations. 